\title{
PENERAPAN ALGORITMA GENETIKA UNTUK PENENTUAN BATASAN FUNGSI KENGGOTAAN FUZZY TSUKAMOTO PADA KASUS PERAMALAN PERMINTAAN BARANG
}

\author{
Rifki Setya Armanda ${ }^{1}$, Wayan Firdaus Mahmudy ${ }^{2}$ \\ Fakultas Ilmu Komputer, Universitas Brawijaya, Malang \\ email: ${ }^{1}$ rifkisetyaarmanda@gmail.com, ${ }^{2}$ wayanfm@ub.ac.id
}

(Naskah masuk: 01 Oktober 2016, diterima untuk diterbitkan: 20 Oktober 2016)

\begin{abstract}
Abstrak
Perencanaan kapasitas produksi seharusnya menyesuaikan dengan kebutuhan permintaan. Hal ini bisa dicapai dengan melakukan peramalan permintaan barang yang diproduksi. Sistem inferensi fuzzy Tsukamoto bisa diimplementasikan untuk peramalan. Salah satu permasalahan dalam penerapan metode fuzzy adalah sulitnya menentukan batasan fungsi keanggotaan yang tepat. Pada tulisan ini diusulkan penggunaan algoritma genetika untuk memperbaiki batasan fungsi keanggotaan fuzzy sehingga didapatkan hasil peramalan yang lebih akurat. Percobaan komputasi membuktikan bahwa sistem inferensi fuzzy yang telah dioptimasi mampu memberikan hasil yang lebih akurat. Dalam hal ini penerapan algoritma genetika untuk penentuan batasan fungsi pada kasus peramalan permintaan barang dilakukan dengan menggunakan teknik extended intermediate crossover, mutasi dengan exchange point dan seleksi dengan menggunakan elitsm selection. Pada penelitian ini terdapat 4 tahapan dalam menentukan nilai error yang optimal dengan menggunakan algoritma genetika sebagai batasan fungsi keanggotaan fuzzy tsukamoto. Data yang digunakan dalam penelitian ini sebanyak 25 permintaan produksi dalam satuan minggu selama tahun 2015. Solusi optimal diperoleh pada ukuran populasi sebanyak 80 , jumlah generasi sebesar 120, dan kombinasi crossover rate dan mutation rate sebesar 0.3 dan 0.7 dengan fitness sebesar 6.863533684 .
\end{abstract}

Kata Kunci: Algoritma genetika, Peramalan, Sistem inferensi fuzzy Tsukamoto

\section{Abstract}

Production capacity planning should be based on the amount of demand needs. This objective can be achieved by using demand forecasting of the products. Tsukamoto Fuzzy Inference System can be implemented for forecasting. However, determining appropriate fuzzy membership function in not easy task. This study proposes genetic algorithms to adjust boundaries of fuzzy membership function so more accurate result will be achieved. A computational experiment proves that the optimized Tsukamoto Fuzzy Inference System can produce more accurate prediction. In this case the application of genetic algorithm for determining the function limitation in case of forecasting the demand for goods is done by using the technique extends intermediate crossover, mutation and selection of the exchange point by using elitism selection. In this study, there are 4 stages in determining the optimal error value by using a genetic algorithm as a limitation Tsukamoto fuzzy membership functions. The data used in this study were 25 requests a week of production in units for 2015. The optimal solution is obtained on the population size of 80, the amount of generation of 120, and the combination of crossover rate and mutation rate of 0.3 and 0.7 with fitness of 6.863533684.

Keywords: genetic algorithms, forecasting, Tsukamoto fuzzy inference system

\section{PENDAHULUAN}

Industri manufaktur memiliki tingkatan persaingan yang sangat ketat. Setiap perusahaan dituntut meningkatkan kemampuan bersaingnya dengan tujuan produk yang dipasarkan dapat diterima pasar. Dalam menyikapi permasalahan tersebut setiap perusahaan harus mampu mengetahui permintaan barang produksi yang akan datang. Peramalan suatu permintaan barang merupakan hal yang diperhitungkan untuk dimasa selanjutnya atau masa yang akan datang berdasarkan data-data permintaan yang dimiliki sebelumnya. Dengan adanya suatu peramalan dalam permintaan barang, maka suatu perusahaan dapat mencapai tujuan serta mengambil keputusan dalam memproduksi barang agar dapat memenuhi keinginan permintaan pasar.

Menurut Nasution dan Prasetyawan (2008), peramalan permintaan diharapkan akan terealisir untuk jangka waktu tertentu pada masa yang akan datang, peramalan permintaan tersebut akan menjadi masukan yang sangat penting dalam mengambil 
keputusan perencanaan dan pengendalian suatu perusahaan. Namun dalam kegiatan peramalan memerlukan penerapan metode yang optimal dalam menghasilkan suatu peramalan permintaan. Hal tersebut bertujuan agar dapat mengetahui tingkat permintaan yang akan datang dan meminimumkan kesalahan pada perhitungan peramalan. Apabila nilai dalam permalan yang kurang tepat, maka akan menyebabkan ketidaksesuaian kuantitas dan kualitas produk dengan permintaan pasar.

Pada penelitian ini ditujukan untuk mengetahui peramalan permintaan barang produksi semen. Sistem yang akan dibangun dalam penelitian ini mampu menghasilkan nilai akurasi yang tepat dalam meramalakan suatu permintaan barang. Sistem inferensi fuzzy Tsukamoto bisa diimplementasikan untuk peramalan. Salah satu permasalahan dalam penerapan metode fuzzy adalah sulitnya menentukan batasan fungsi keanggotaan yang tepat (Azizah dkk., 2015, Achnas dkk., 2015). Pada tulisan ini diusulkan penggunaan algoritma genetika untuk memperbaiki batasan fungsi keanggotaan fuzzy sehingga didapatkan hasil peramalan yang lebih akurat.

\section{PENELITIAN TERKAIT}

Beberapa penelitian sebelumnya telah membahas mengenai permasalahan prediksi dan pengendalian persediaan. Misalnya pada penelitian yang dilakukan oleh Indroprasto dan Suryani (2012) dengan permasalahan pengendalian persediaan produk dengan metode EOQ menggunakan Algoritma Genetika yang bertujuan agar dapat mengifisiensikan biaya persediaan.

Beberapa penelitian yang berkaitan tentang peramalan atau prediksi dengan menggunakan Algoritma Genetika telah dilakukan oleh Rahmi dan Mahmudy (2016) yang menerapkan Algoritma Genetika dalam membentuk regresi untuk memprediksi harga saham, Penelitian tersebut menunjukan bahwa Algoritma Genetika mampu memberikan hasil nilai prediksi yang mendekati nilai atau data aslinya

\section{METEDOLOGI}

\subsection{Data Uji}

Dalam pengolahan data terdapat beberapa langkah yang harus dilakukan, antara lain:

1. Pada pengamatan langsung terdapat data jumlah permintaan barang semen di setiap minggunya.

2. Menghitung total jumlah permintaan barang yang dihasilkan pada perusahaan Koperasi Warga Semen Gresik (KWSG) dengan mengakumulasikan jumlah permintaan dan jumlah persediaan pada setiap minggunya.

Data sampel yang didapatkan berupa data primer yaitu data permintaan barang semen yang dilakukan oleh Perusahaan Koperasi Semen Gresik (KWSG) setiap minggunya. Data permintaan barang semen didapatkan sebanyak 25 minggu dimulai dari bulan Januari sampai dengan bulan Juli 2015.

\subsection{Siklus Penyelesaian Masalah Sistem Inferensi Fuzzy Tsukamoto}

Metode Fuzzy Tsukamoto merupakan metode yang sesuai dalam memprediksi jumlah permintaan selanjutnya. Dalam perhitungan Fuzzy Tsukamoto memiliki 4 kriteria, antara lain T3, T2, T1, dan T. T3 merupakan kriteria data permintaan barang 3 minggu sebelumnya, kemudian pada T2 merupakan kriteria data permintaan barang 2 minggu sebelumnya, lalu pada T1 merupakan kriteria data permintaan barang 1 minggu sebelumnya, dan pada $\mathrm{T}$ merupakan kriteria data permintaan barang minggu selanjutnya.

Fungsi keanggotaan permintaan barang 3 minggu sebelumnya (T3) adalah:

\section{Rendah}

$$
\mu_{x=n A=4}[x]\left\{\begin{array}{cc}
1_{2} & x \leq 8000 \\
\frac{8500-x}{500}, & 8000 \leq x \leq 8500 \\
0, & x \geq 8500
\end{array}\right.
$$

Sedang

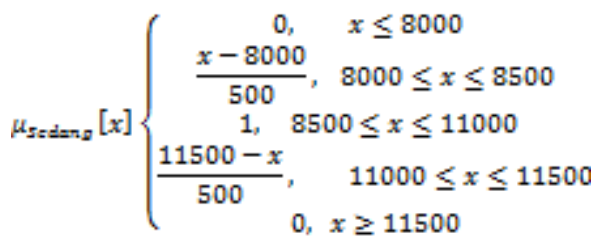

Tinggi

$\mu_{\text {mingsi }}[x]\left\{\begin{array}{rl}0, & x \leq 11000 \\ \frac{x-11000}{500}, & 11000<x<11500 \\ 1_{a} & x \geq 11500\end{array}\right.$

Untuk kriteria lain bisa dibentuk serupa. Permasalahannya adalah bagaimana menentukan batasan fungsi keanggotaan yang tepat. Hal ini bisa ditentukan menggunakan algoritma genetika.

\subsection{Siklus Penyelesaian Masalah Menggunakan Algoritma Genetika}

Algoritma genetika mampu memberikan solusi dalam menyelesaikan masalah dengan mencari kemungkinan-kemungkinan dari calon solusi (populasi). Solusi yang dicari adalah satu atau lebih titik diantara solusi yang layak dalam ruang pencarian. Penyelesaian masalah menggunakan algoritma genetika memerlukan beberapa tahapan sebagai berikut:

1. Membuat populasi awal secara radom sebagai batasan-batasan dalam metode fuzzy tsukamoto. Pembentukan populasi awal sebanyak 4 kriteria, kemudian melakukan 
pembentukan populasi awal secara berurutan sesuai dengan kriteria yang digunakan

2. Melakukan reproduksi dengan crossover extends intermediate dan mutasi exchange point pada pembentukan awal populasi.

3. Seleksi dengan metode elitism.

4. Menentukan nilai fitnes agar mendapatkan solusi akhir yang optimal. Berikut merupakan persamaan perhitungan dalam mengetahui nilai fitness pada metode algoritma genetika

$$
\text { fitness }=\frac{10000}{\text { RMSE }} \text { (2) }
$$

5. Iterasi dilakukan untuk generasi berikutnya.

\subsection{Reprentasi Kromosom dan Perhitungan Fitness}

Reprentasi kromosom merupakan proses pengkodean dari penyelesaian suatu permasalahan (Mahmudy, Marian \& Luong, 2013). Reprentasi kromosom pada penelitian ini menggunakan pengkodean real (real code). Pada pengkodean real memiliki hasil yang optimal dalam permasalahan optimasi, sebab pengkodean real dapat menjangkau beberapa titik solusi jika range solusi berada pada daerah kontinyu Reprentasi real code juga digunakan oleh Samaher dan Mahmudy (2015) dalam permasalahan memaksimalkan laba produksi.

Pembentukan kromosom inisial pada penelitian ini dengan membangkitkan nilai random yang didapatkan dari jumlah permintaan barang semen dari suplier pada setiap minggunya. Angka pada gen menunjukkan batasan fungsi keanggotaan.

\section{HASIL DAN PEMBAHASAN}

\subsection{Uji Coba Ukuran Populasi}

Uji coba yang pertama dilakukan adalah uji coba ukuran populasi terhadap perubahan nilai fitness. Dalam pengujian ini jumlah generasi yang digunakan adalah 5 dengan crossover rate sebesar 0,6 dan mutation rate sebesar 0,4 .

Jumlah data yang digunakan adalah 25 data permintaan barang perminggunya pada bulan Januari sampai dengan bulan Juni. Pada setiap ukuran populasi dilakukan sebanyak 10 kali percobaan sehingga memperoleh nilai rata-rata fitness.

Ukuran populasi diuji pada kelipatan 20, mulai dari 20 sampai dengan 200, sehingga terdapat 10 ukuran popSize yang berbeda. Hasil grafik uji coba ukuran populasi ditunjukkan pada Gambar 1.

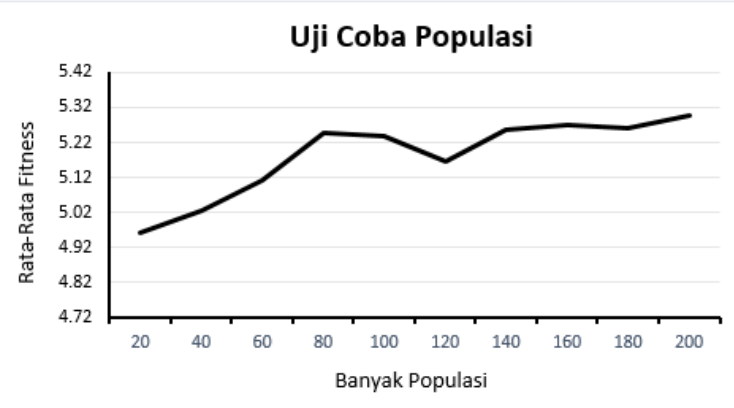

Gambar 1 Hasil Uji Coba Ukuran Populasi

Hasil uji coba ukuran populasi pada Gambar 1, dapat terlihat perbedaan hasil pengujian ukuran populasi terhadap nilai fitness yang dihasilkan. Dari hasil tersebut didapatkan bahwa ukuran populasi 80 merupakan hasil ukuran populasi yang dianggap optimal dengan rata-rata nilai fitness 5.248283825, sebab setelah jumlah populasi 80 sulit untuk mendapatkan nilai fitness yang lebih baik.

Besar nilai fitness dalam penelitian ini sangat dipengaruhi oleh besarnya ukuran populasi. Semakin besar ukuran populasi maka semakin besar juga nilai fitness yang dihasilkan. Akan tetapi jika ukuran populasi terlalu besar, kemungkinan akan sulit dalam memperoleh hasil nilai yang optimal dan terlalu besar ukuran populasi yang digunakan maka waktu dalam memproses perhitungan akan semakin lama. Kondisi seperti ini disebut juga dengan kondisi konvergensi, artinya hampir semua kromosom bernilai sama sehingga akan menghasilkan offspring yang hampir sama dengan induknya yang dapat menyebabkan eksploitasi dalam memberikan solusi kurang baik (Mahmudy, 2015).

\subsection{Hasil dan Uji Coba Banyaknya Generasi}

Uji coba yang kedua adalah uji coba jumlah generasi terhadap perubahan nilai fitness. Setelah melakukan pengujian terhadap ukuran populasi maka hasil yang didapatkan akan digunakan dalam pengujian jumlah generasi.

Pada setiap generasi akan dilakukan pengujian nilai fitness sebanyak 10 kali dan didapatkan jumlah rata-rata nilai fitnessnya. Kemudian nilai rata-rata fitness tersebut akan ditampilkan dalam bentuk grafik untuk mengetahui jumlah generasi yang optimal dengan ukuran populasi optimal sebesar 80 , nilai crossover rate 0.6 , nilai mutation rate 0.4 , jumlah generasi sebanyak 5 dan jumah data yang digunakan sebesar 25 .

Hasil grafik uji coba banyaknya generasi dapat dilihat pada Gambar 2. 


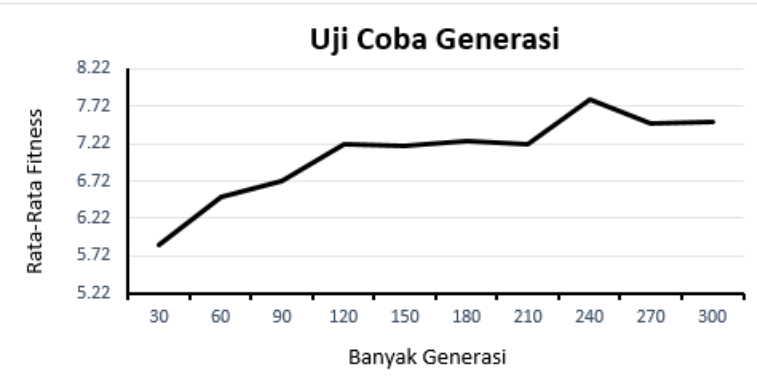

Gambar 2 Hasil Uji Coba Generasi

Hasil banyaknya generasi yang optimal didapatkan pada jumlah generasi 120 dengan nilai rata-rata fitness 7.213717573. Jumlah generasi 120 merupakan solusi yang optimal dalam uji coba jumlah generasi, sebab jumlah generasi setelah 120 sangat sulit untuk menetukan nilai fitness yang lebih besar lagi. Hal tersebut terjadi karena adanya kondisi konvergensi setelah jumlah generasi 120 .

\subsection{Hasil dan Uji Coba Kombinasi Cr dan Mr}

Pengujian selanjutnya adalah pengujian untuk mendapatkan nilai optimal dari kombinasi $\mathrm{Cr}$ dan Mr. Dalam uji coba kombinasi $\mathrm{Cr}$ dan $\mathrm{Mr}$ jumlah populasi yang digunakan sebesar 80, jumlah generasi sebanyak 120 dan jumlah data yang digunakan sebesar 25 data. Hasil grafik kombinasi cr dan mr ditunjukan pada Gambar 3.

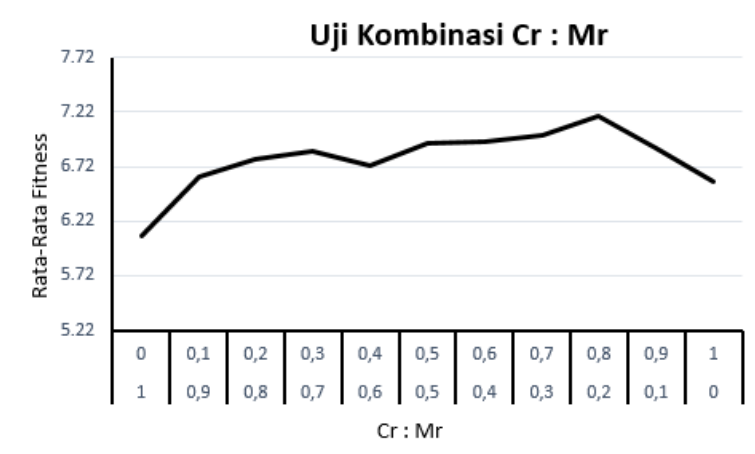

Gambar 3 Hasil Uji Coba Cr dan $\mathrm{Mr}$

Pada Gambar 3 dapat dilihat bahwa nilai fitness dengan rata-rata terbaik ada pada kombinasi Crossover sebesar 0.3 dan mutation sebesar 0.7 dengan nilai rata-rata fitness sebesar 6.863533684 . Pada nilai kombinasi crossover dengan jumlah 0 dan mutation sebesar 1 merupakan nilai rata-rata fitness yang terkecil dengan nilai rata-rata fitness sebesar 6.5761184. Dengan nilai crossover rate yang tinggi dan mutation rate dengan nilai yang rendah, maka algoritma genetika akan mengalami penurunan kemampuan dalam menjaga diversitas populasi sehingga mengalami konvergensi dini hanya dalam beberapa generasi serta kehilangan kesempatan untuk mengeksplorasi area lain dalam ruang pencairan. Akan tetapi bila nilai crossover rate yang terlalu rendah dan nilai mutation rate yang lebih tinggi maka algoritma genetika akan sangat bergantung pada proses mutasi (Mahmudy, Marian \& Luong, 2013). Kesimpulan yang didapat dalam uji coba kombinasi crossover rate dan mutation rate adalah nilai rata-rata fitness yang tertinggi ada pada nilai $0.3: 0.7$.

\subsection{Hasil dan Uji Coba Parameter Terbaik}

Setelah melakukan pengujian ukuran populasi, jumlah generasi, kombinasi $\mathrm{Cr}$ dan $\mathrm{Mr}$ dan jumlah data yang digunakan, maka pengujian selanjutnya adalah uji coba menggunakan parameter terbaik. Dalam uji coba menggunakan parameter terbaik menggunakan kombinasi $\mathrm{Cr}$ dan $\mathrm{Mr}$ yang sebesar $0.3: 0.7$, jumlah populasi yang digunakan sebesar 80 , jumlah generasi sebanyak 120 , dan jumlah data yang digunakan sebesar 25. Hasil dari pengujian dengan menggunakan nilai parameter terbaik dapat dilihat pada Tabel 1 .

Tabel 1 Hasil Pengujian Parameter Terbaik

\begin{tabular}{|c|c|}
\hline Percobaan ke- & Nilai fitness \\
\hline 1 & 7.191586222 \\
\hline 2 & 6.960106285 \\
\hline 3 & 7.107569854 \\
\hline 4 & 7.5834942 \\
\hline 5 & 7.109786478 \\
\hline 6 & 7.460262386 \\
\hline 7 & 6.897202871 \\
\hline 8 & 6.98818738 \\
\hline 9 & 7.245711885 \\
\hline 10 & 7.13895194 \\
\hline Rata-Rata Fitness & $\mathbf{7 . 1 6 8 2 8 6}$ \\
\hline
\end{tabular}

Tabel 1 menujukkan hasil rata - rata nilai fitness tertinggi yang didapatkan sebesar 7.168286. Pada Tabel 2 dan Tabel 3 menjelaskan hasil perbandingan nilai error (RMSE) yang didapatkan pada metode perhitungan fuzzy tsukamoto dan metode perhitungan algoritma genetika.

Berikut pada Tabel 2 merupakan hasil perhitungan metode fuzzy tsukamoto pada studi kasus peramalan permintaan barang.

Tabel 2 Hasil Perhitungan Fuzzy Tsukamoto

\begin{tabular}{|c|c|c|c|c|}
\hline Minggu & Permintaan & $\begin{array}{l}\text { Tsukamoto } \\
\text { \& Algoritma } \\
\text { Genetika }\end{array}$ & $\begin{array}{l}\text { Error (Data } \\
\text { Permintaan- } \\
\text { Hasil Prediksi) }\end{array}$ & $\begin{array}{l}\text { Error (Data Permintaan- } \\
\text { Hasil Prediksi)^2 }\end{array}$ \\
\hline 1 & 13543 & N/A & N/A & N/A \\
\hline 2 & 11957 & $\mathrm{~N} / \mathrm{A}$ & N/A & N/A \\
\hline 3 & 15016 & $\mathrm{~N} / \mathrm{A}$ & $\mathrm{N} / \mathrm{A}$ & $\mathrm{N} / \mathrm{A}$ \\
\hline 4 & 9990 & 11500 & -1510 & 2280100 \\
\hline 5 & 8785 & 11500 & -2715 & 7371225 \\
\hline 6 & 8389 & 8500 & -111 & 12321 \\
\hline 7 & 11776 & 8327,3 & 3448,7 & 11893531,69 \\
\hline 8 & 12297 & 8883,5 & 3413,5 & 11651982,25 \\
\hline 9 & 11067 & 11327,3 & $-260,3$ & 67756,09 \\
\hline 10 & 11239 & 11384 & -145 & 21025 \\
\hline \multicolumn{4}{|c|}{ Total } & 33297941,03 \\
\hline & & & Total $/ 7$ & 4756848.719 \\
\hline & & & RMSE & 2181.02011 \\
\hline
\end{tabular}


Pada Tabel 2 menunjukan bahwa nilai error yang didapatkan dengan perhitungan fuzzy tsukamoto adalah sebesar 5770,44.

Pada Tabel 3 merupakan hasil perhitungan menggunakan algoritma genetika pada studi kasus peramalan permintaan barang

Tabel 3 Hasil Perhitungan Algoritma Genetika

\begin{tabular}{|c|c|c|c|c|}
\hline Minggu & Permintaan & $\begin{array}{c}\text { Tsukamoto } \\
\text { \& Algoritma } \\
\text { Genetika }\end{array}$ & $\begin{array}{c}\text { Error (Data } \\
\text { Permintaan- } \\
\text { Hasil Prediksi) }\end{array}$ & $\begin{array}{l}\text { Error (Data Permintaan- } \\
\text { Hasil Prediksi) }\end{array}$ \\
\hline 1 & 13543 & - & - & - \\
\hline 2 & 11957 & - & - & - \\
\hline 3 & 15016 & - & - & - \\
\hline 4 & 9990 & 10957.45 & -967.45 & 935959.5025 \\
\hline 5 & 8785 & 7098.9 & 1686.1 & 2842933.21 \\
\hline 6 & 8389 & 7098.9 & 1290.1 & 1664358.01 \\
\hline 7 & 11776 & 10437.16667 & 1338.833333 & 1792474.694 \\
\hline 8 & 12297 & 11104.82 & 1192.18 & 1421293.152 \\
\hline 9 & 11067 & 12243.63333 & -1176.633333 & 1384466.001 \\
\hline 10 & 11239 & 10957.45 & 281.55 & 79270.4025 \\
\hline \multicolumn{4}{|c|}{ Total } & 10120754.97 \\
\hline & & & Total $/ 7$ & 1445822.139 \\
\hline & & & RMSE & 1202.42 \\
\hline
\end{tabular}

Tabel 3 menunjukan bahwa nilai error yang didapatkan dengan perhitungan algoritma genetika adalah sebesar sebesar 1202.42.

\section{SIMPULAN}

Dari hasil pengujian yang telah dilakukan dalam penelitian ini, metode Algoritma Genetika dan Fuzzy Tsukamoto dapat memberikan nilai error yang lebih rendah dalam studi kasus peramalan permintaan barang. Pada Implementasi dalam peramalan permintaan barang Semen menggunakan Algoritma Genetika dan Fuzzy Tsukamoto, solusi pada ukuran populasi terbaik adalah 80 popsize, solusi pada jumlah generasi terbaik adalah 120 , untuk solusi kombinasi nilai crossover rate (cr) dan mutation rate (mr) didapatkan $0.3: 0.7$.

Dalam penelitian ini, metode Algoritma Genetika mampu menghasilkan nilai yang optimal dalam hal meprediksi atau meramalkan suatu permintaan barang semen. Cara penyelesaian dalam Algoritma Genetika pada penelitian ini menggunakan beberapa metode seperti Extended Intermediate Crossover, Reciprocal Exchange Mutation dan Elitism Selection. Hasil dari penelitian ini pada peramalan menggunakan Algoritma Genetika dan Fuzzy Tsukamoto mendapatkan nilai error yang lebih rendah.

Dengan menggunakan metode Algoritma Genetika di dalam perhitungan Fuzzy Tsukamoto pada studi kasus peramalan permintaan barang mampu menghasilkan nilai yang optimal dibandingkan dengan melakukan perhitungan dengan metode Fuzzy Tsukamoto, sebab batasanbatasan yang digunakan dalam menetukan nilai Tinggi, Sedang, Rendah pada Fuzzy Tsukamoto dilakukan secara acak yang didapatkan dari nilai data permintaan minggu sebelumnya yang kemudian nilai yang didapatkan akan di urutkan berdasarkan dari nilai terkecil hingga terbesar pada setiap kriteria yang digunakan.

\section{SARAN}

Pada penelitan selanjutnya diharapkan menggunakan metode selain Fuzzy Tsukamoto untuk dapat digabungkan dengan metode Algoritma Genetika dalam studi kasus peramalan atau prediksi permintaan barang.

Dalam penelitian selanjutnya juga diharapkan mampu mendapatkan jumlah data yang lebih banyak lagi dengan tujuan mendapatkan variasi pengujian yang dilakukan agar mendapatkan nilai hasil yang lebih optimal, sebab pada penelitian ini masih tebatas dalam mendapatkan data permintaan barang.

\section{DAFTAR PUSTAKA}

Azizah, EN, Cholissodin, I \& Mahmudy, WF. 2015, 'Optimasi fungsi keanggotaan fuzzy tsukamoto menggunakan algoritma genetika untuk penentuan harga jual rumah', Journal of Environmental Engineering \& Sustainable Technology, vol. 2, no. 2, pp. 79-82.

Achnas, AH, Cholissodin, I \& Mahmudy, WF 2015, 'Optimasi fuzzy inference system sugeno dengan algoritma hill climbing untuk penentuan harga jual rumah', Journal of Environmental Engineering \& Sustainable Technology, vol. 2, no. 1, pp. 31-36.

Mahmudy, WF, Marian, RM \& Luong, LHS. 2013, 'Modeling and optimization of part type selection and loading problems in flexible manufacturing system using real coded genetic algorithms', International Journal of Electrical, Computer, Electronics and Communication Engineering, vol. 7, no. 4, pp. 251-260.

Indroprasto \& Suryani, E. 2012. 'Analisis Pengendalian Persediaan dengan Metode EOQ Menggunakan Algoritma genetika untuk Mengefisiensikan Biaya Persediaan'. Jurnal Teknik, Institut Teknologi Sepuluh Nopember (ITS).

Nasution, Hakim, A, \& Prasetyawan, Y. 2008. Perencanaan \& Pengendalian Produksi. Graha Ilmu, Yogyakarta.

Rahmi, A \& Mahmudy, WF 2016, 'Pembentukan model regresi harga saham menggunakan algoritma genetika', Seminar Nasional Teknologi Informasi dan Komunikasi (SENTIKA), Yogyakarta, 18-19 Maret.

Samaher \& Mahmudy, WF 2015, 'Penerapan algoritma genetika untuk memaksimalkan laba produksi jilbab', Journal of Environmental Engineering \& Sustainable Technology, vol. 2, no. 1, pp. 6-11. 